\title{
FROM OSS CAD TO BIM FOR CULTURAL HERITAGE DIGITAL REPRESENTATION
}

\author{
S. Logothetis, E. Karachaliou, E. Stylianidis \\ Faculty of Engineering, School of Spatial Planning \& Development \\ Aristotle University, Thessaloniki, 54124, Greece \\ slogothet@auth.gr; ekaracha@plandevel.auth.gr; sstyl@auth.gr
}

Commission II

KEY WORDS: CAD, BIM, FOSS, HBIM

\begin{abstract}
:
The paper illustrates the use of open source Computer-aided design (CAD) environments in order to develop Building Information Modelling (BIM) tools able to manage 3D models in the field of cultural heritage. Nowadays, the development of Free and Open Source Software (FOSS) has been rapidly growing and their use tends to be consolidated. Although BIM technology is widely known and used, there is a lack of integrated open source platforms able to support all stages of Historic Building Information Modelling (HBIM) processes. The present research aims to use a FOSS CAD environment in order to develop BIM plug-ins which will be able to import and edit digital representations of cultural heritage models derived by photogrammetric methods.
\end{abstract}

\section{INTRODUCTION: FROM CAD TO BIM}

The past years in the field of AEC (Architecture, Engineering, Construction), the typical way to represent a model on a paper by hand, was replaced by the use of digital and advanced CAD tools, which reinforced the creation, modification, analysis, or optimisation of design models (Garagnani and Manferdini, 2013). CAD systems imported information technology (IT) in the design process by using specialised software in order to represent any object with graphics and create databases for storing the models. All the design process, from problem identification to the implementation, was being run by the user/designer, however, the CAD system was assisting the user in a series of activities. Indicatively, to generate easily and with accuracy the graphical model of the object, to manage in short time complex design analysis, to store and recall the model and modify it (Bilalis, 2000).

Sketchpad is considered as the world's first CAD software, dated by in 1963 (Sutherland, 2003). It was written by Ivan Sutherland in the course of his $\mathrm{PhD}$ for which he received the Turing Award in 1988, the "Nobel Prize of computing".

Many years later, the first CAD systems, were implementing only $2 \mathrm{D}$ modelling and they were able to process entity objects as graphic symbols, representing only the geometrical properties of each element (Ibrahim and Krawczyk, 2003). Nowadays, the evolution in the field of CAD technology revealed the parametric modelling mostly represented by BIM.

Building Information Modelling can be considered as an advanced CAD approach, which extends the capability of the traditional design methodology by applying and defining intelligent relationships between the elements in the designed model (Garagnani and Manferdini, 2013). BIM models face the object entity not only as a graphic symbol but as an integrated entity allowing different level of information (geometric and nongeometric) to be included as well as pointing the relations among all the items of the model (Czmocha and Pekala, 2014).

Thus allowing BIM to be considered as the next generation of the CAD systems.

\section{BUILDING INFORMATION MODELLING}

\subsection{BIM Technology}

BIM is a five dimensions (5D) digital representation of a building, a structure or an environment with its physical and functional characteristics. It consists of intelligent building components or characteristics of environments which include parametric rules and data attributes for each object (Hergunsel, 2011). The five dimensions are as follows: the three (3D) primary spatial dimensions (width, height and depth), the fourth dimension (4D) is time and the fifth (5D) is cost.

The most important capabilities of the BIM technology are the following: to ensure integration management of graphical and informational data flows; to combine the graphical interface with the information flows and process descriptions; to develop the strategy of building project design, to construction and maintenance management; to perform life cycle operations of a construction project more faster, effective and with lower cost; to transform individual executors into teams and decentralise tools into complex solutions, this leading to individual tasks being implemented as complex processes (Popov et al., 2006).

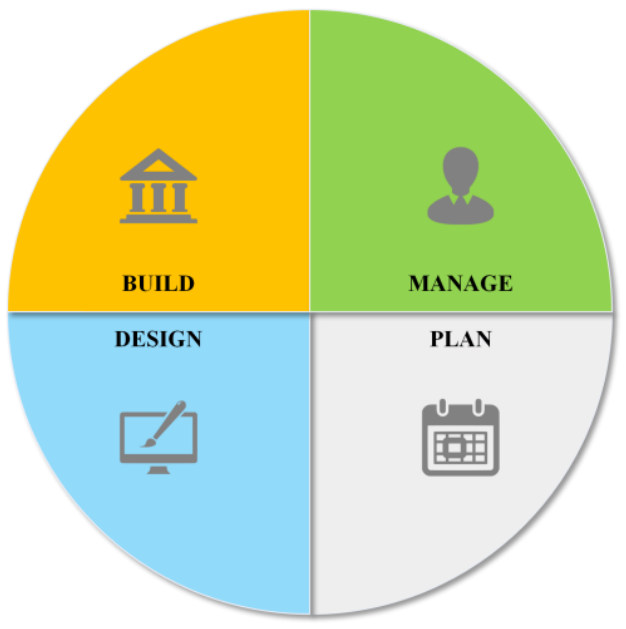

Figure 1: BIM Model 
BIM model provides an accurate overall picture to the project team (architects, civil engineers, surveyors, conservators, contractors, etc.) (Fig. 1). One of the most important BIM's characteristics is the provision of a reliable basis for timely and rapid decisions, assisting the involved staff to increase quality and productivity in the design but also during project implementation. Since, BIM has largely evolved in the recent years by providing high quality information, the technology help to reduce risks and defects in all stages of a project (Logothetis et al., 2015).
In BIM systems is commonly used the Industry Foundation Classes (IFC) data model as a collaboration format, intend to describe building and construction industry data. In fact, it is an open file format with a data model developed by buildingSMART to facilitate interoperability in the AEC industry (Eynon, 2016).

The available BIM platforms nowadays, can be distinguish in the different sets of tools, as illustrated in Table 2 (Logothetis et al., 2015).

\begin{tabular}{|c|c|c|c|c|}
\hline Product name & Manufacturer & BIM use & Primary function & Supplier web link \\
\hline Revit Architecture & Autodesk & $\begin{array}{l}\text { Creating and reviewing } \\
\text { 3D models }\end{array}$ & $\begin{array}{l}\text { Architectural modelling } \\
\text { and parametric design }\end{array}$ & $\underline{\text { www.autodesk.com }}$ \\
\hline Bentley Architecture & Bentley Systems & $\begin{array}{l}\text { Creating and reviewing } \\
\text { 3D models }\end{array}$ & Architectural modelling & www.bentley.com \\
\hline SketchUpPro & Google & $\begin{array}{l}\text { Conceptual 3D } \\
\text { Modelling }\end{array}$ & $\begin{array}{l}\text { Conceptual design } \\
\text { modelling }\end{array}$ & www.sketchup.google.com \\
\hline ArchiCAD & Graphisoft & $\begin{array}{l}\text { Conceptual 3D } \\
\text { architectural model }\end{array}$ & $\begin{array}{l}\text { Architectural model } \\
\text { creation }\end{array}$ & www.graphisoft.com \\
\hline TeklaStructures & Tekla & $\begin{array}{l}\text { Conceptual 3D } \\
\text { modelling }\end{array}$ & $\begin{array}{l}\text { Architectural 3D model } \\
\text { application }\end{array}$ & www.tekla.com \\
\hline DProfiler & Beck Technology & $\begin{array}{l}\text { Conceptual design and } \\
\text { cost estimation }\end{array}$ & $\begin{array}{l}\text { 3D conceptual modelling } \\
\text { with real-time cost } \\
\text { estimating }\end{array}$ & www.beck-technology.com \\
\hline Vectorworks Designer & Nemetschek & $\begin{array}{l}\text { Conceptual 3D } \\
\text { modelling }\end{array}$ & $\begin{array}{l}\text { Architectural model } \\
\text { creation }\end{array}$ & www.nemetschek.net \\
\hline Affinity & Trelligence & $\begin{array}{l}\text { Conceptual 3D } \\
\text { modelling }\end{array}$ & $\begin{array}{l}\text { A 3D model application } \\
\text { for early concept design }\end{array}$ & www.trelligence.com \\
\hline Vico Office & Vico Software & $\begin{array}{l}\text { Conceptual 5D } \\
\text { modelling }\end{array}$ & $\begin{array}{l}\text { 5D conceptual model } \\
\text { which can be used to } \\
\text { generate cost and } \\
\text { schedule data }\end{array}$ & $\underline{\text { www.vicosoftware.com }}$ \\
\hline Revit Structure & Autodesk & Structural & $\begin{array}{l}\text { Structural modelling and } \\
\text { parametric design }\end{array}$ & $\underline{\text { www.autodesk.com }}$ \\
\hline $\mathrm{SDS} / 2$ & Design Data & Structural & $\begin{array}{l}\text { 3D structural modelling } \\
\text { and detailing }\end{array}$ & $\underline{\text { www.dsndata.com }}$ \\
\hline RISA & $\begin{array}{l}\text { RISA } \\
\text { Technologies }\end{array}$ & Structural & $\begin{array}{l}\text { Full suite of structural } \\
\text { design applications } \\
\text { for steel, wood, concrete, } \\
\text { and masonry }\end{array}$ & $\underline{\text { www.risatech.com }}$ \\
\hline Robot & Autodesk & Structural analysis & $\begin{array}{l}\text { Bi-directional link with } \\
\text { Autodesk Revit structure }\end{array}$ & $\underline{\text { www.autodesk.com }}$ \\
\hline Green Building Studio & Autodesk & Energy analysis & $\begin{array}{l}\text { Measure energy use and } \\
\text { carbon footprint }\end{array}$ & $\underline{\text { www.autodesk.com }}$ \\
\hline Ecotect & Autodesk & Energy analysis & $\begin{array}{l}\text { Weather, energy, water, } \\
\text { carbon emission analysis }\end{array}$ & www.autodesk.com \\
\hline $\begin{array}{l}\text { Structural Analysis } \\
\text { Design Detailing, } \\
\text { Building Performance }\end{array}$ & Bentley Systems & $\begin{array}{l}\text { Structural } \\
\text { analysis/detailing, } \\
\text { quantity take-off, } \\
\text { building performance }\end{array}$ & $\begin{array}{l}\text { Measure, assess and } \\
\text { report building } \\
\text { performance }\end{array}$ & $\underline{\text { www.bentley.com }}$ \\
\hline Solibri Model Checker & Solibri & $\begin{array}{l}\text { Model checking \& } \\
\text { validation }\end{array}$ & $\begin{array}{l}\text { Rules-based checking for } \\
\text { compliance and } \\
\text { validation of all objects } \\
\text { in the model }\end{array}$ & www.solibri.com \\
\hline Tekla BIMSight & Tekla & Model viewer & $\begin{array}{l}\text { Combine models, check } \\
\text { for clashes and share } \\
\text { information }\end{array}$ & www.teklabimsight.com \\
\hline xBIM Xplorer & Open BIM & IFC viewer & $\begin{array}{l}\text { Open, view IFC files and } \\
\text { navigate through a model }\end{array}$ & http://xbim.codeplex.com \\
\hline Solibri Model Viewer & Solibri & Model viewer & $\begin{array}{l}\text { Open all standard IFC } \\
\text { and Solibri model } \\
\text { checker files }\end{array}$ & $\underline{\text { www.solibri.com }}$ \\
\hline
\end{tabular}

Table 1. Existing BIM tools (Logothetis et al., 2015) 


\begin{tabular}{|l|l|}
\hline \multicolumn{1}{|c|}{ Type of tools } & \multicolumn{1}{c|}{ Role } \\
\hline $\begin{array}{l}\text { Tools for design } \\
\text { 3D models (3D } \\
\text { modellers) }\end{array}$ & $\begin{array}{l}\text { Which represent the real BIM tools, } \\
\text { working with solid, parametric objects } \\
\text { in sufficient features to virtually } \\
\text { construct the building. }\end{array}$ \\
\hline $\begin{array}{l}\text { Tools of } \\
\text { projection/visualis } \\
\text { ation models } \\
\text { (Viewers/Surface } \\
\text { modellers) }\end{array}$ & $\begin{array}{l}\text { Which aid to realise how the building } \\
\text { will "look", a surface modeller or a } \\
\text { viewer (all shapes are empty). }\end{array}$ \\
\hline $\begin{array}{l}\text { Tools of } \\
\text { calculating } \\
\text { analysis of } \\
\text { models }\end{array}$ & $\begin{array}{l}\text { Which are third-party software that } \\
\text { communicate to the main BIM tool, } \\
\text { e.g. analyse data from the 3D modeller } \\
\text { to determine the model's energy } \\
\text { efficiency or day lighting (see } \\
\text { http://www.awci.org/pdf/bim.pdf). }\end{array}$ \\
\hline
\end{tabular}

Table 2. Types of BIM platforms

\subsection{HBIM for cultural heritage}

As BIM technology was initially developed in order to serve the needs of the construction industry, BIM environments were structured to generate and manage from zero parametric geometries and create objects using existing libraries of shapes and conditions. Nevertheless, the past decade, a remarkable development and use of BIM technology in the field of cultural heritage has been occurred (Logothetis et al., 2015). In the case of cultural heritage documentation, the objects consist of components and materials whose geometry and characteristics are not represented by libraries of typical software, thus the Historic BIM (HBIM) approach was developed referring to the process by which the architectural elements collected using a terrestrial laser scanner and produced photogrammetric survey data are converted into parametric objects (Dore and Murphy, 2012). In that way, it is possible to document and manage any size or complex form of a cultural heritage object (Singh et al., 2011).

Concerning the HBIM technology, its complexity and diversity led to the development of specific software that offer several possibilities to their users allowing them to deal with various categories of historical structures information. The majority of these tools are commercial software and in most cases quite expensive and inaccessible. Table 1, summarises the most wellknown of them.

\section{BIM AND POINT CLOUD GENERATION TOOLS FOR CULTURAL HERITAGE}

\subsection{The case of REVIT Autodesk}

To date, the most commonly used BIM software is the Autodesk Revit, which actually is a commercial platform. Autodesk Revit (Version 2016) is a BIM software, which includes features for architectural design, mechanical, electrical or plumbing (MEP), construction, and structural engineering. It allows to use the intelligent model-based process to design, plan, construct, and manage buildings and infrastructure, supporting by that way collaborative design with a multidiscipline design process (Autodesk, 2016). It gives the possibility to the user to create a mass model with a combination of void and solid forms. The faces of the mass volume can be converted into building elements and floors and other architectural elements can be generated inside the mass model (Boeykens et al., 2008).
Revit BIM software, supports the open XML-based IFC standard (developed by the buildingSMART organisation), which allows the parties involved to the project (i.e. client, contractor etc.) to require and obtain BIM-based workflow from the different discipline consultants of a building project (Logothetis et al., 2015).

\subsection{Scan to BIM add-on}

Revit software includes some add-on menus that add functionalities and capabilities to the software. There are two categories:

a) extensions which are developed and supplied by Autodesk

b) supplements that are developed and provided by other companies working in partnership with Autodesk to facilitate the modelling of their products (Autodesk, 2016)

In terms of photogrammetry and laser scanning, the creation of three-dimensional representations of cultural heritage objects is based on point clouds generation and processing. In this concept, "Scan to BIM" supplement, developed by IMAGINiT Technologies, allows to illustrate into Revit environment, a point cloud that has been previously generated through a photogrammetric or laser scanning process, Fig. 2.

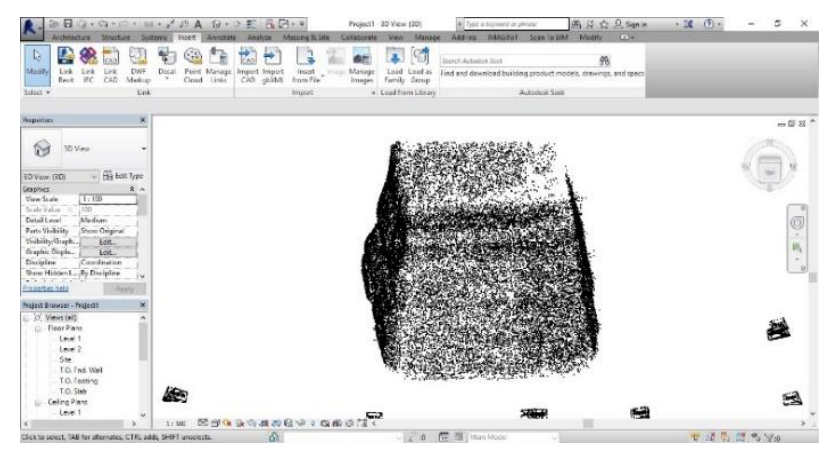

Figure 2. Revit interface hosts a point cloud

"Scan to BIM" add-on supports a model creation and validation from a point cloud through automated recognition and placement of architectural elements (i.e. columns, walls, MEP elements such as pipes, ducts, conduits etc) (IMAGINiT, 2016).

Some key features of the "Scan to BIM" add-on include (IMAGINiT, 2016):

- Tools to assist with creation of Revit elements including: walls, columns, ducts, levels, and pipes.

- Construction geometry to assist with other element types.

- Mesh modelling.

- Clean topography extraction.

- Automated recognition of walls across an entire Revit point cloud.

- Supports interference/clearance detection for geometry versus point cloud.

- Viewing enhancements to quickly create useful views and toggle point cloud viewing options.

- Workflow-based tools to help set up, work on and quality check your model with the point cloud.

- Measure points within the scan to quickly find true dimensions.

- Align/extend existing geometry to match the point cloud. 
In the AEC industry the conversion of a selected part of the point cloud into a mesh representation - either in the model or as a family - it is considered as a very useful process. This can be made by "Create Mesh" (Fig. 3) feature of the Scan to BIM that let users to model complex details with relative ease. Moreover, allows the user to build native Revit geometry from a point cloud as well as to analyze differences between the model geometry and the point cloud (IMAGINiT, 2016). "Create mesh" is a function that serves a lot the needs of historical restoration modeling and preservation projects (IMAGINiT, 2016).

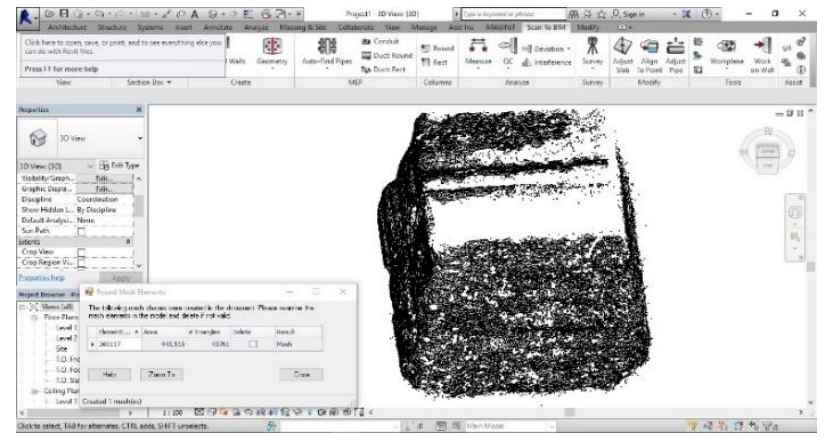

Figure 3. Create mesh from point clouds (Revit add-on: "Scan to BIM")

Even tough, many technological advances have taken place in the field of HBIM software, and software like Revit are widely known and used, unfortunately in the field of open source there are no integrated platforms able to support all stages of HBIM process. A recent survey showed that there is no available, wellrespected and comprehensive FOSS BIM platform to be used for the overall cultural heritage documentation project. The lack of such a (FOSS) platform persistently outlines the real need for the development of plug-ins in different areas of the BIM software, which could be freely available to a large community of professional designers, architects, engineers and conservators but also for the research community for applied research (Logothetis and Stylianidis, 2016).

In this context, the present work aims to investigate the possibility of developing and show the conceptual design of such plug-in tools, freely available for the professional and scientific community. This work is using an open source CAD environment in order to develop a BIM plug-in which will be able to import and edit digital representations of cultural heritage models derived by photogrammetric methods. Therefore, by using the advantages that an open source software offers, this work aims to enhance CAD's environment services with BIM characteristics.

\section{FREE \& OPEN SOURCE SOFTWARE (FOSS)}

\subsection{Brief description}

The Open Source Software (OSS) means that the source code, i.e. any group of computer instructions written using a humanreadable computer language, is freely accessible by everyone erested in. The software can be freely used, copied, improved, changed and distributed by anyone and for any purpose (Statskontoret, 2003).

Free software is a term coined by a programmer in MIT Artificial Intelligence Lab, namely Richard Matthew Stallman. According to Stallman, free software means the freedom that can get everyone to use the software. Without any permission required, the software can be freely used, modified and redistributed
(Ambar et al., 2010). As Steiniger and Hunter (2012) underline, the benefits of a free and open source software are its freedom to be run it for any purpose, to be adapted for the users' own needs, to be improved and have such improvements released to the public.

\subsection{FOSS CAD \& FOSS BIM}

The abilities and diversity of BIM technology is obvious in many fields and for this reason there are specific software, mainly commercial that offers several possibilities to their users. However, in the field of open source there are no integrated platforms to cover all stages of BIM process. Many users prefer commercial software BIM instead of FOSS because there is not a credible and comprehensive platform that can be used for the overall 5D digital representation of a building. There are only a few, accessible and free BIM viewers to visualise the final produced model (Logothetis and Stylianidis, 2016), as presented previously in Table 1.

In the family of CAD software, widely known and mostly used worldwide, especially among the architecture and mechanical engineering field, is the commercial Autodesk's software "AutoCAD". However, very interesting free and open source $\mathrm{CAD}$ environments exist, some of which allow the users to exploit the programming environment inside the platform and extend their possibilities.

Among the available FOSS CAD and 3D graphics software, is FreeCAD, Blender, SketchUp, B-Processor, which are widely known and used by designers, engineers and modellers communities. Each of them has specific characteristics that differentiate it from the rest, whilst all of them are offering a variety of functions.

As shown in Table 3, some of them are open source while some others are freeware; meaning that are free but it is not possible for the user to intervene the source code and extend its functionalities. Differences are also observed in their Application Programming Interface (API) while the majority of them can be run both in Windows and Mac environment. Moreover, a deeper investigation through some forums which are active on the field (i.e. "alternativeto.net", "cad.softwareinsider.com"), shows that the users are more interested in reviewing FreeCAD and SketchUp capabilities and improvement possibilities.

\begin{tabular}{|r|c|c|c|c||}
\hline & \multicolumn{4}{|c|}{ FOSS 3D Graphics, CAD \& BIM software } \\
\cline { 2 - 5 } & FREECAD & BLENDER & SKETCHUP & B-PROCESSOR \\
\hline 3D & $\mathrm{X}$ & $\mathrm{X}$ & $\mathrm{X}$ & $\mathrm{X}$ \\
\hline License & $\mathrm{OS}$ & $\mathrm{OS}$ & Freeware & OS \\
\hline Extensions & $\mathrm{X}$ & $\mathrm{X}$ & $\mathrm{X}$ & $\mathrm{X}$ \\
\hline Available extensions & $\mathrm{X}$ & $\mathrm{X}$ & $\mathrm{X}$ & - \\
\hline Programming API & Python & Python & Ruby & Java \\
\hline Use & 3D CAD & 3D modelling & 3D CAD & BIM \\
\hline Up to date & $18 / 6 / 2016$ & 30/9/2016 & $7 / 11 / 2016$ & $15 / 11 / 2016$ \\
\hline Runs on Unix & $\mathrm{X}$ & $\mathrm{X}$ & - & - \\
\hline Runs on Windows & $\mathrm{X}$ & $\mathrm{X}$ & $\mathrm{X}$ & $\mathrm{X}$ \\
\hline Runs on Mac & $\mathrm{X}$ & $\mathrm{X}$ & $\mathrm{X}$ & - \\
\hline Community & $\mathrm{X}$ & $\mathrm{X}$ & $\mathrm{X}$ & - \\
\hline
\end{tabular}

Table 3. FOSS 3D graphics, CAD and BIM characteristics

The aim of this work is to use an open source CAD environment in order to extend its capabilities and develop a FOSS BIM plugin the area of cultural heritage documentation (Fig. 4). To meet this objective, the following criteria have been set:

1. A FOSS software that will be open source and not freeware.

2. The software should be able to accept extensions, with preferable programming API to be Python. 


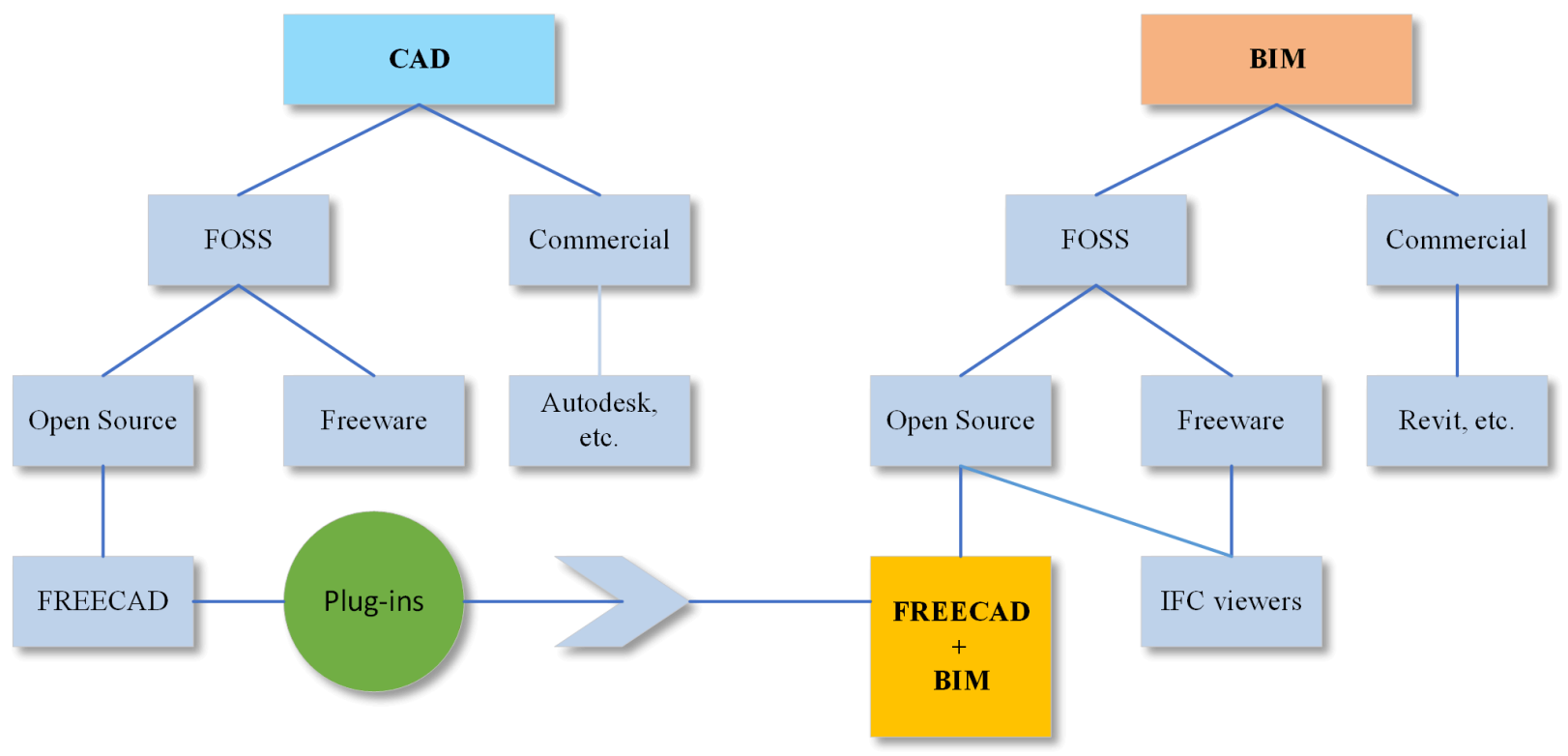

Figure 4. Concept of plugin development

3. It should also be available for all types of operating systems (UNIX, Windows, Mac) and commonly used and accepted by the users'.

Within this concept, the FOSS parametric FreeCAD software was selected for further development, as this package meets all the requirements set.

\section{TOWARDS A FOSS BIM}

\subsection{Free CAD}

FreeCAD (Version 0.16) is a FOSS 3D CAD modeller that originally aimed towards a wide range of sectors of applied engineering. It is open-source and extremely customisable, scriptable and extensible.

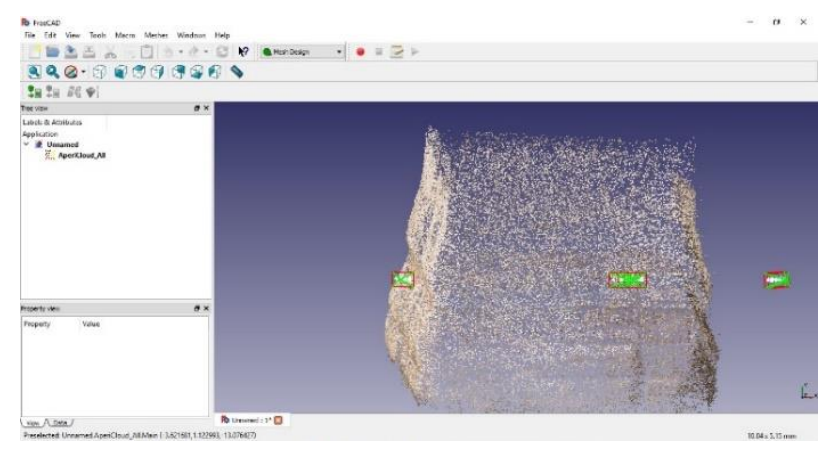

Figure 5. Point clouds shown in FreeCAD

New functions and open source libraries can be added without modifying the main core system. It includes an embedded Python interpreter, and thus someone can use Python code into the software. The provision of additional functionalities that will manipulate parts of FreeCAD, for example to create mesh from imported point clouds, is made easy (Fig. 5) (Collette and Falck, 2012).

In the field of 3D modelling, FreeCAD system has served a number of times as subject of research work. Carl Schultz et al. (2015), used FreeCAD to demonstrate the way a parametric model may be constrained by the spatial aspects of conceptual design specifications and higher-level semantic design requirements, involving a combination of topological, visibility, and movement constraints, Guimaraes et al. (2016) used FreeCAD for 3D modelling geometry and assembling objects and Horneber et al. (2014) used FreeCAD to build ".stl" files of different 3D structures.

\subsection{Extending FreeCAD into BIM}

An integrated BIM model, is able to display $3 \mathrm{D}$ entities which are directly linked with additional layers of information. That way, it's possible the advanced analysis of the model with extra information that permits cost analysis, calculation of energy consumption, structural resistance, estimation of construction time, etc.

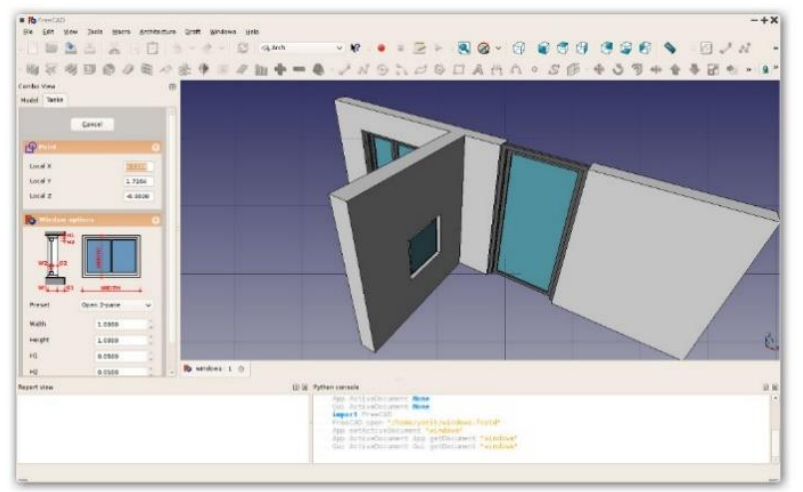

Figure 6. Creating with Arch Module, (FreeCADweb, 2016)

FreeCAD, includes a tool called "Arch module" (Fig. 6), which implements a series of tools and facilities modelling. It can allow BIM workflow, however, it does not include the same tools and level of completion such as the commercial alternatives (i.e. Revit) and moreover it is still under development (FreeCADweb, 2016).

FreeCAD does not include a complete add-on that implements 4D (time scheduling) and 5D (cost estimating) model analysis. 
Within this context, the current work aims to develop a plug-in which will serve a comprehensive and integrated BIM model analysis. The referenced plug-in focus on three new functions:

- Mesh generation from point cloud

- $\quad 4 \mathrm{D}$ - time scheduling (Gantt chart) and

- $\quad 5 \mathrm{D}$ - cost estimation

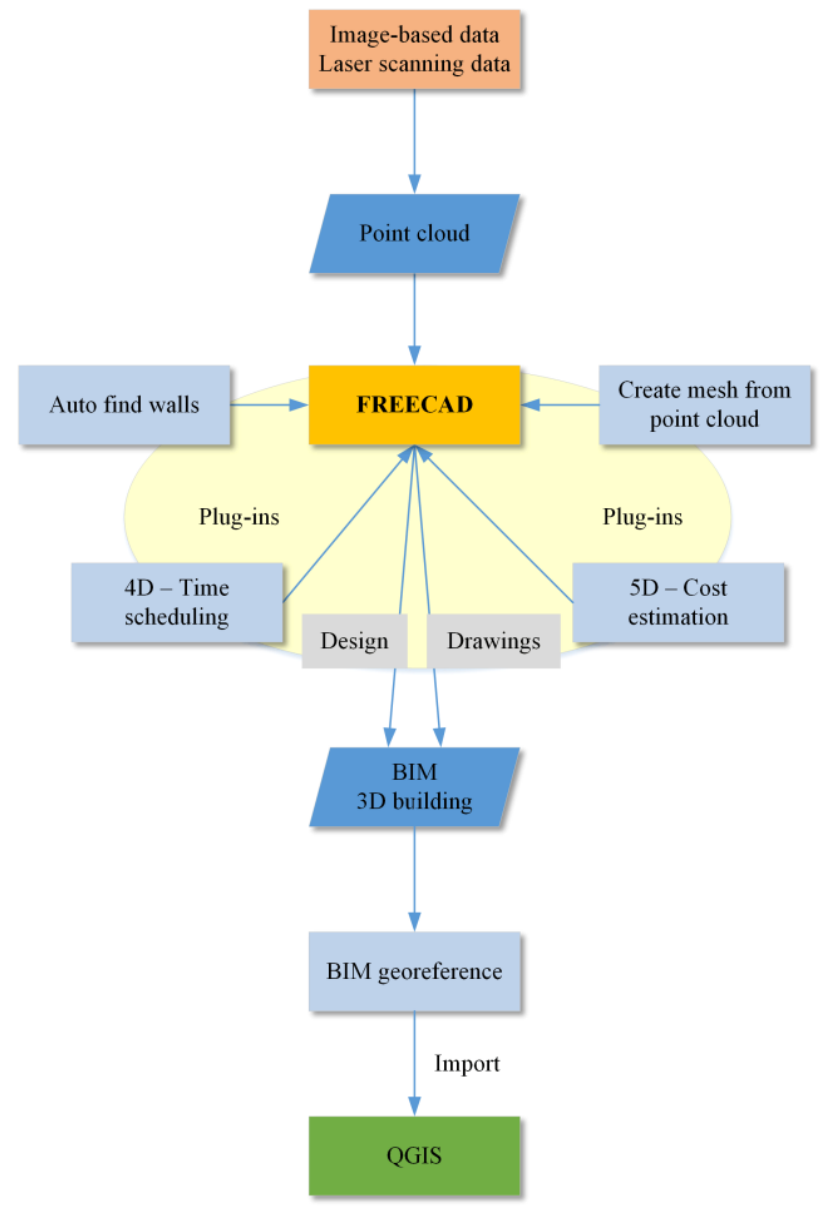

Figure 7. Workflow of plug-in under development

The designed workflow of the final tool is shown in Fig. 7 and follows the steps:

a) Import the point cloud model into the FreeCAD environment for further processing exploiting all $\mathrm{CAD}$ functionalities.

b) Process the point cloud inside the CAD environment and generate a BIM model by using the new plug-in and the appropriate design and drawing functions.

c) Extend BIM model utilities by georeferencing and integrate the 3D data model into QGIS which also offers useful capabilities as an open source software in the area of GIS.

The plugin (extension) in FreeCAD is called module. Workbench is a special GUI configuration that groups some toolbars and module may contains a workbench. The module will be developed in Python using a special python script; namely the FreeCAD Build tool. In addition, Qt Designer will be used as a tool for designing and building the appropriate graphical user interfaces (GUIs), and then, convert it to python code so to be usable within FreeCAD.

\section{CONCLUSIONS \& FUTURE WORK}

Based on the fact that up-to-date there is no available free and open source BIM platform, this paper has presented a new idea of using a FOSS CAD software in order to extend its capabilities and transform it gradually into a FOSS BIM platform. This can be used in a variety of application, including the cultural heritage documentation field.

By setting some specific criteria such as the programming API, the possibility to intervene, modify and extend the source code, the operating systems and the users' preference, we concluded to the case of FreeCAD software. After investigating its functionalities, a workflow was set which proposes the development and the integration of a set of plug-ins, which will boost the software with advanced BIM services.

As the new developments are implemented for the new FOSS BIM platform, the resulting models can utilise the full benefits of an open source architecture.

\section{REFERENCES}

Ambar, K., Debashish, S., Sitanath, B., 2010. Application of Free and Open source software and its Impact on society. International Journal of Computer Science and Information Technologies, Vol. 1 (4), pp. 226 229.

Bilalis, N., 2000. Computer Aided Design CAD. Report produced for the EC funded project INNOREGIO: dissemination of innovation and knowledge management techniques, Technical University of Crete.

Boeykens, S., Neuckermans, H., 2008. Scale Level and Design Phase Transitions in a Digital Building Model. http://citeseerx.ist.psu.edu/viewdoc/download?doi=10.1.1.93.315\&rep= rep1\&type=pdf (28 Dec. 2016).

Collette, B. Falck, D., 2012. FreeCAD [How-To], Packt Publishing Limited, Birmingham, UK.

Czmocha, I., Pekala, A., 2014. Traditional Design versus BIM Based Design. XXIII R-S-P seminar, Theoretical Foundation of Civil Engineering, Procedia Engineering, Vol. 91, pp. 210-215.

Dore, C., Murphy, M., 2012. Integration of historic building information modeling and 3D GIS for recording and managing cultural heritage sites, 18th International Conference on Virtual Systems and Multimedia: "Virtual Systems in the Information Society", Milan, Italy, pp. 369-376, http://dx.doi.org/10.1109/VSMM.2012.6365947 (6 Jan. 2017).

Eynon, J., 2016. Construction Manager's BIM Handbook, ISBN: 978-1118-89647-1, Wiley-Blackwell.

Foundation of the Wall and Ceiling Industry, 2009. Building Information Modeling: Understanding and Operating in a New Paradigm, Falls Church, https://www.bakertriangle.com/assets/BIM-white-paper.pdf (7 Jan. 2017).

Garagnani, S., Manferdini, A., 2013. Parametric Accuracy: Building Information Modeling Process Applied to the cultural heritage preservation. 3D-ARCH 2013 - 3D Virtual Reconstruction and Visualization of Complex Architectures. Trento, Italy, pp. 87-92.

Guimaraes, A.V., Brasileiro, P.C., Giovanni, G.C., Costa, L.R.O., Araujo, L.S., 2016. Failure analysis of a half-shaft of a formula SAE racing car, Case Studies in Engineering Failure Analysis 7, pp. 17-23. 
Hergunsel, M. F., 2011. Benefits of Building Information Modeling for Construction Managers and BIM-based scheduling, Worcester Polytechnic Institute.

Horneber, T., Rauh, C., Delgado, A., 2014. Numerical simulations of fluid dynamics in carrier structures for catalysis: characterization and need for optimization, Chemical Engineering Science Vol. 117, pp. 229238.

Ibrahim, M., Krawczyk, R., 2003. The Level of Knowledge of CAD Objects within the Building Information Model. Illinois Institute of Technology, http://mypages.iit.edu/ krawczyk/miacad03.pdf (17 Jan. 2017).

Logothetis, S., Delinasiou, A., Stylianidis, E., 2015. Building Information Modelling for Cultural Heritage: A review. ISPRS Annals of the Photogrammetry, Remote Sensing and Spatial Information Sciences, Volume II-5/W3, 25th International CIPA Symposium 2015, Taiwan, pp. $177-183$.

Logothetis, S., Stylianidis, E., 2016. BIM Open Source Software (OSS) for the documentation of Cultural Heritage. Proceedings of the 8th International Congress on Archaeology, Computer Graphics, Cultural Heritage and Innovation 'ARQUEOLÓGICA 2.0', Valencia, Spain, pp. 28-35 http://dx.doi.org/10.4995/var.2016.5864 (27 Dec. 2016).

Popov, V., Mikalauskas, S., Migilinskas, D., Vainiunas, P., 2006. Complex Usage of 4D Information Modeling Concept for Building Design, Estimation, Scheduling, and Determination of Effective Variant. Technological and Economic Development of Economy, 12(2), pp. 9198.

Schultz, C., Bhatt, M., Borrmann, A., 2015. Bridging qualitative spatial constraints and feature-based parametric modelling: Expressing visibility and movement constraints, Advanced Engineering Informatics, Vol.31, pp. 2-17.

Singh, V., Gu, N., Wang, X., 2011. A theoretical framework of a BIMbased multi-disciplinary collaboration platform. Automation in Construction, 20(2), 134-144 http://dx.doi.org/10.1016/j.autcon.2010.09.011 (15 Jan. 2017).

Statskontoret, 2003. Free and Open Source Software - a feasibility study. Available: http://www.statskontoret.se/globalassets/publikationer/20002005-english/200308a.pdf (20 Dec. 2016).

Steiniger, S., Hunter, A. J., 2012. The 2012 free and open source GIS software map - A guide to facilitate research, development, and adoption. Computers, Environment and Urban Systems, Vol.39, pp. 136-150.

Sutherland, I., 2003. Sketchpad: a man-machine graphical communication system. Technical Report. University of Cambrigde, UCAM-CL-TR-574, ISSN 1476-2986.

http://www.autodesk.com/products/revit-family/overview

https://www.freecadweb.org/

http://www.imaginit.com/software/imaginit-utilities-otherproducts/scan-to-bim/Tab/Documents 